\title{
Perfil da incidência e da sobrevida de pacientes com carcinoma epidermóide oral em uma população brasileira
}

\section{Incidence and survival profile of patients with oral squamous cell carcinoma in a Brazilian population}

Lucinei Roberto de Oliveira'; Alfredo Ribeiro-Silva²; Sergio Zucoloto ${ }^{3}$

\begin{abstract}
unitermos
Câncer de boca

Carcinoma de células escamosas

Fatores de risco

Incidência

Sobrevida

\section{resumo}

Introdução: A incidência do câncer bucal no Brasil é uma das mais altas do mundo. Objetivos: Avaliar o perfil, os fatores de risco e a sobrevida de pacientes diagnosticados com carcinoma epidermóide oral entre 1982 e 2002 em uma população brasileira. Material e método: Idade, gênero, local da lesão, história pregressa, consumo de tabaco e bebidas alcoólicas, exposição actínica, traumatismo por prótese, recidivas, metástases e sobrevida foram obtidos dos prontuários. Resultados: Dos 340 pacientes $84,4 \%$ eram homens e $15,6 \%$, mulheres $(5,4: 1)$. As lesões linguais foram as mais freqüentes $(27,9 \%)$. Vinte por cento dos pacientes relataram traumatismo por prótese e em $73,8 \%$ das lesões em lábio inferior foi relatada exposição actínica desprotegida. Não houve diferença entre as regiões anatômicas e o consumo de tabaco em relação a recidivas, metástases regionais e metástases à distância. O tempo médio de história pregressa foi de 13 meses, havendo diferença entre as regiões anatômicas. A sobrevida em cinco anos foi de $24 \%$. A sobrevida dos pacientes com recidivas e/ou metástases variou conforme a idade analisada ( $\leq 60$ ou $>$ 60 anos), mas não houve diferença quanto à história pregressa e às regiões anatômicas. A discrepância homem/mulher encontrada foi alta, diminuindo conforme o aumento da idade. O consumo de tabaco e álcool é elevado nessa população, mas não influenciou as recidivas e as metástases da doença. Foi grande o tempo de evolução das lesões até a procura pelo serviço. Conclusões: Os baixos índices de sobrevida refletem a necessidade de uma maior atenção ao câncer bucal nessa população.
\end{abstract}

abstract

Background: The buccal cancer incidence in Brazil is one of the highest in the world. Objectives: To evaluate profile, risk factors and survival in patients with oral squamous cell carcinoma between 1982 and 2002 in a Brazilian population. Material and method: Age, gender, tumor site, previous clinical history, tobacco and alcohol consumption, actinic exposure, trauma by dental prosthesis, recurrences, metastases and survival rates were obtained from the medical files. Results: From 340 patients, $84.4 \%$ were men and 15.6\%, women (5.4:1). The lingual lesions were the most frequent ones (27.9\%). Twenty percent of the patients reported trauma by dental prosthesis and in $73.8 \%$ of the lesions in lower lip an unprotected actinic exposure was reported. There was no difference between anatomical region and tobacco consumption concerning recurrences and regional or distant metastases. The average time of previous clinical history was 13 months, with significant differences among the anatomical regions. The 5-year-old survival rates were $24 \%$. The survival rate of patients with recurrences and/or metastases varied according to age ( $\leq 60$ or $>60)$, but not to previous medical history or anatomical regions. The man/woman discrepancy found was high, but decreased according to the rise of age. Tobacco and alcohol consumption is elevated in this population, but did not influence recurrences and metastases. The time of evolution of the lesions was long until the search for medical service. Conclusions: The low survival rates reflect the need of a more careful attention to buccal cancer in this population.

\section{key words}

Oral cavity cancer

Squamous cell carcinoma

Risk factors

Incidence

Survival

1. Doutorando do Programa de Pós-Graduação em Patologia Experimental, Departamento de Patologia da Faculdade de Medicina de Ribeirão Preto, Universidade de São Paulo (FMRP/USP).
2. Professor-doutor do Departamento de Patologia da FMRP/USP.

3. Professor titular do Departamento de Patologia da FMRP/USP. 


\section{Introdução}

A maioria dos estudos envolvendo lesões orais não separa as regiões específicas dentro da cavidade oral. No entanto, as localizações mais comuns relatadas são terço anterior da língua, lábios, assoalho bucal e palato duro(14). É de fundamental importância a distinção da região da orofaringe, que inclui palato mole, base da língua, região tonsilar e faringe posterior, onde as características clínicas, o prognóstico da lesão e a sensibilidade à radioterapia são distintos ${ }^{(14,34)}$.

Aproximadamente $10 \%$ dos tumores malignos que ocorrem no corpo humano estão localizados na boca ${ }^{(38)}$, sendo esse o sexto tipo de câncer mais incidente no mundo ${ }^{(47)}$. Excluindo-se o câncer de pele, o câncer bucal pode ser considerado o mais comum da região de cabeça e pescoço $(38 \%)^{(8,11)}$, predomina no sexo masculino, tem $75 \%$ dos casos diagnosticados na faixa etária dos 60 anos $^{(6)}$ e cerca de $95 \%$ dos casos são carcinomas epidermóides( ${ }^{(9)}$.

De acordo com as estatísticas mundiais, no ano 2002, aproximadamente 274 mil novos casos de câncer bucal foram diagnosticados e cerca de 128 mil pacientes foram a óbito por esse tipo de neoplasia. A região de maior incidência é a Melanésia (31,5 casos por 100 mil homens e 20,2 casos por 100 mil mulheres), seguida pelo Sul da Ásia (12,7 casos por 100 mil homens e 8,3 casos por 100 mil mulheres) ${ }^{(35)}$.

No Brasil, o câncer de boca é o oitavo tipo de câncer mais freqüente entre os homens (9.985 casos estimados/ ano) e o nono entre as mulheres (3.895 casos estimados/ ano) $)^{(17)}$ e suas taxas de incidência e mortalidade vêm aumentando, sendo consideradas das mais altas do mundo. Para o ano de 2005, segundo estimativas do INCA, cerca de 14 mil novos casos seriam diagnosticados, sendo $60 \%$ deles na Região Sudeste ${ }^{(17)}$.

O estado de São Paulo possui uma das maiores taxas brutas de incidência no país para cada 100 mil habitantes, sendo de 17,77 e 5,59 para os gêneros masculino e feminino, respectivamente ${ }^{(17)}$. Além disso, concentra $32 \%$ e trata cerca de $42 \%$ de todos os casos de câncer bucal do país ${ }^{(17)}$. Já a cidade de São Paulo possui a maior taxa de incidência do continente americano, com 25,3 e 4,9 para os gêneros masculino e feminino, respectivamente ${ }^{(51)}$.

Apesar de ainda não haver uma clara compreensão da etiologia do câncer, vários fatores determinantes têm sido detectados e investigados. O conhecimento dos fatores de risco constitui a base para uma prevenção efetiva da doença. Mesmo sendo o câncer de boca uma doença multifatorial, o tabaco e o álcool são os dois fatores de risco mais importantes não só para o desenvolvimento da neoplasia, como também para seu prognóstico(4). Entre os demais fatores que determinam seu prognóstico estão região anatômica, tamanho e espessura, comprometimento ganglionar, tratamento e diferenciação tumoral( ${ }^{(48)}$.

A incidência do carcinoma epidermóide oral difere significativamente entre os países, assim como dentro do Brasil, fato que se deve possivelmente às diferenças locais na prevalência dos fatores de risco. Estudos populacionais concernentes ao câncer bucal e seus fatores de risco são escassos em nosso país(51). Devido à alta incidência do câncer bucal no estado de São Paulo, situando-se entre uma das maiores do mundo, o objetivo deste estudo retrospectivo foi avaliar o perfil e os fatores de risco dos pacientes diagnosticados com carcinoma epidermóide oral no Hospital das Clínicas da Faculdade de Medicina de Ribeirão Preto, Universidade de São Paulo (HC-FMRP/USP), avaliando alguns parâmetros de sobrevida e comparando-os com a literatura atual existente para definir fatores implicados no diagnóstico precoce e no prognóstico da doença.

\section{Material e métodos}

O projeto de pesquisa, sob o no 7327/2004, foi integralmente aprovado pelo Comitê de Ética em Pesquisa do HC-FMRP/USP. Os dados do trabalho foram obtidos analisando-se os prontuários do Serviço de Arquivo Médico do HC-FMRP/USP entre os anos de 1982 e 2002. Foram selecionados os prontuários médicos dos pacientes que tiveram o diagnóstico de carcinoma epidermóide oral confirmado por biópsia e que possuíam material arquivado em parafina no Departamento de Patologia da FMRP/USP.

Na seleção dos prontuários foram obtidas informações sobre história pregressa da lesão, idade, gênero, local da lesão, consumo de tabaco e bebidas alcoólicas, exposição actínica, traumatismo por prótese, recidivas, metástases e sobrevida. Para a classificação dos pacientes tabagistas e/ou etilistas, foram utilizados os critérios de Carvalho et al.(6), aplicados apenas de maneira qualitativa. As lesões classificadas como bucais encontravam-se em palato duro, gengiva, dois terços anteriores da língua, lábios, mucosa jugal, assoalho, mucosa alveolar e retromolar. Foram excluídas as lesões em orofaringe, que inclui palato mole, base da língua, região tonsilar, úvula e faringe posterior.

Os dados foram analisados estatisticamente com o teste não-paramétrico de Mann-Whitney para correlacionar idade e gênero. Utilizando o teste qui-quadrado, foram analisadas a 
topografia da lesão com traumatismo por prótese, recidivas, metástases e a história pregressa. Verificamos a incidência de recidivas e metástases em tabagistas e não-tabagistas pelo teste de Fischer e analisamos a sobrevida dos pacientes conforme história pregressa, idade, topografia e ocorrência de recidivas e metástases. Para o estudo da sobrevida foram selecionados os pacientes sem nenhum antecedente de câncer de cabeça e pescoço e sem tratamento radioterápico prévio. Foram excluídos os pacientes com metástases iniciais, tumores in situ e T4, além daqueles com mortes por outras causas. A sobrevida global foi calculada a partir do início do tratamento até o último seguimento ou óbito do paciente. Foi considerado um nível de significância de 5\%. As curvas de sobrevivência foram estimadas usando o método KaplanMeier ${ }^{(19)}$. Todos os testes estatísticos foram realizados com o programa GraphPad Prism, versão 4.0 (San Diego, CA).

\section{Resultados}

Foram analisados 340 casos de carcinoma epidermóide oral diagnosticados por biópsia entre 1982 e 2002. Os gêneros dos pacientes foram relatados em todos prontuários, sendo 287 (84,4\%) homens e 53 (15,6\%) mulheres $(5,4: 1)$. As idades na época do diagnóstico variaram de 27 a 90 anos, com idade média de 60 anos (57 anos para homens e 62,9 anos para mulheres). A Tabela 1 demonstra a distribuição segundo a idade dos pacientes. A diferença na idade de incidência do carcinoma foi significativa em relação ao gênero $(p=0,0003)$, havendo tendência de afetar mais tardiamente as mulheres. Devido a esse fato, a relação entre os gêneros (masculino/feminino) também mostrou uma variação de acordo com a idade dos pacientes, sendo de cerca de 9:1 antes dos 60 anos e diminuindo para 3,2:1 após essa idade.

Distribuição segundo a idade, em anos, dos pacientes com carcinoma

Tabela 1 epidermóide oral

\begin{tabular}{lcc}
\hline Faixa etária & Número de pacientes & $\%$ \\
\hline até 40 & 29 & 8,5 \\
41 a 50 & 73 & 21,5 \\
51 a 60 & 108 & 31,8 \\
61 a 70 & 86 & 25,3 \\
71 a 80 & 35 & 10,3 \\
81 a 90 & 9 & 2,6 \\
Total & 340 & 100 \\
\hline
\end{tabular}

A distribuição das regiões anatômicas acometidas pela neoplasia está demonstrada na Tabela 2. As lesões linguais foram as mais freqüentes, contribuindo com 95 casos $(27,9 \%)$, número muito próximo daquele de lesões em região de assoalho bucal, com 92 casos (27,1\%).

Nas lesões de lábio inferior, 45 pacientes $(73,8 \%)$ relataram exposição actínica desprotegida durante anos, dois (3,3\%) negaram tal exposição e em 14 prontuários $(22,9 \%)$ não havia a informação. O traumatismo causado por próteses foi relatado por 55 (20\%) pacientes, 129 $(46,7 \%)$ relataram não haver traumatismo e em 92 prontuários (33,3\%) não havia a informação. A Figura 1 ilustra os pacientes que relataram em seus prontuários o trauma por prótese conforme a região anatômica.

Analisando os pacientes que relataram trauma de acordo com a região anatômica, encontramos uma diferença significativa $(p<0,0001)$ entre as seis regiões analisadas. O palato duro foi a topografia mais relacionada, com 23 pacientes (46\%), e a língua foi a região menos associada, com apenas oito $(8,4 \%)$.

\section{Distribuição dos pacientes com carcinoma epidermóide oral}

\begin{tabular}{lcc} 
Região anatômica & Número de pacientes & $\%$ \\
\hline Língua & 95 & 27,9 \\
Assoalho & 92 & 27,1 \\
Lábio inferior & 61 & 17,9 \\
Palato & 50 & 14,7 \\
Retromolar & 20 & 5,9 \\
Mucosa jugal & 11 & 3,2 \\
Gengiva & 8 & 2,4 \\
Lábio superior & 3 & 0,9 \\
Total & 340 & 100 \\
\hline
\end{tabular}

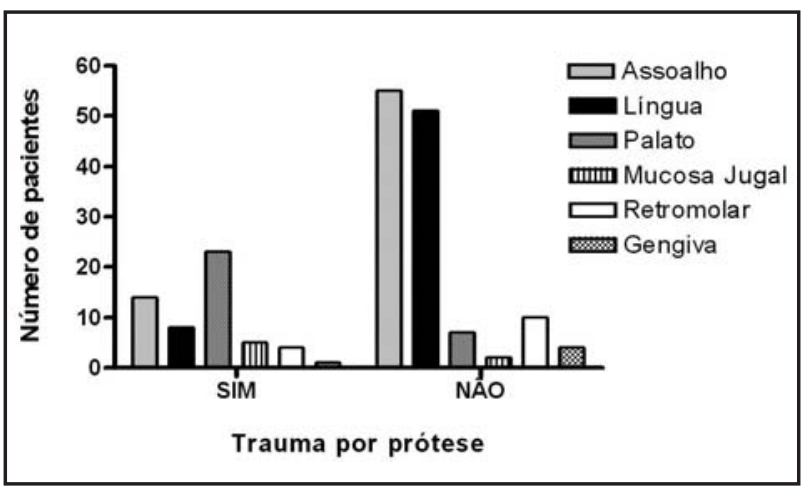

Figura 1 - Relatos de traumatismo crônico por prótese conforme a região anatômica 
Com relação aos principais fatores de risco, 63 pacientes $(18,5 \%)$ relataram ser tabagistas, cinco $(1,5 \%)$ afirmaram ser etilistas, $233(68,5 \%)$ relataram ser tabagistas e etilistas, apenas $16(4,7 \%)$ negaram o uso dessas substâncias e 23 prontuários $(6,8 \%)$ não continham essas informações. Do total de tabagistas, 296 pacientes $(87 \%), 21(7,1 \%)$ relataram consumir cigarros de palha, cinco (1,7\%) afirmaram fumar cachimbo e quatro $(1,4 \%)$ revelaram o hábito de mascar fumo.

As associações entre região anatômica e recidivas, metástases regionais e metástases à distância nos pacientes estudados estão demonstradas na Tabela 3. Não foi encontrada diferença significativa entre as cinco regiões anatômicas de maior incidência ao analisar a ocorrência das recidivas $(p=0,387)$, metástases regionais $(p=0,086)$ e metástases à distância $(p=0,534)$. Apesar da menor incidência, o consumo de tabaco pelos pacientes estudados não apresentou influência estatisticamente significativa nas recidivas e metástases da doença $(p=1,0)$.

Embora a maioria dos pacientes tenha procurado cuidados médicos em até seis meses, o tempo médio encontrado foi de 13 meses. Houve diferença significativa entre a região anatômica e a história pregressa das lesões $(p<0,0001)$ (Figura 2).

Para o estudo da sobrevida foram selecionados 126 pacientes $(37,1 \%)$ do total estudado que tiveram o devido acompanhamento relatado em seus prontuários e enquadravam-se nos critérios do estudo. A taxa de sobrevida global em cinco anos foi de apenas 24\% (Figura 3). Analisando a sobrevida nos pacientes com recidivas e/ou metástases, ou naqueles com ausência de ambos (Figura 4), encontramos uma diferença significativa nas curvas de sobrevida $(p<$
0,0001). A comparação entre as curvas do tempo de sobrevida também foi estatisticamente diferente segundo a idade analisada ( $\leq 60$ ou $>60$ anos), com $p=0,002$ (Figura 5). Por outro lado, não houve diferença significativa conforme a história pregressa $(p=0,297)$ e nas quatro regiões anatômicas de maior incidência $(p=0,139)$ (Figura 6) no estudo da sobrevida dos pacientes analisados.

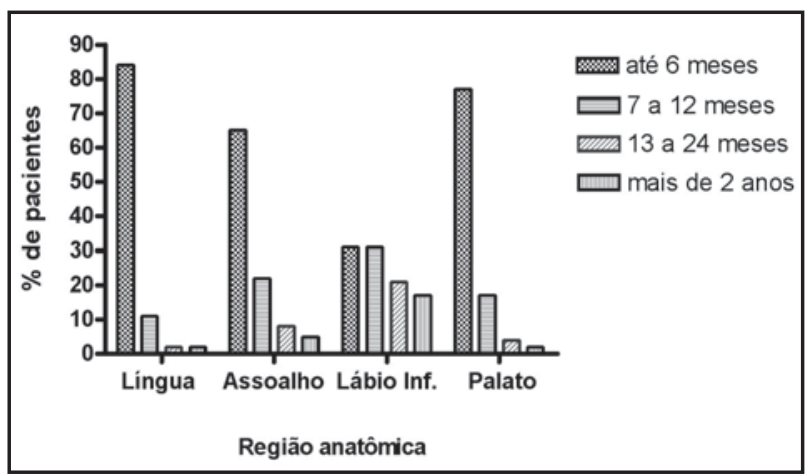

Figura 2 - História pregressa das lesões conforme a região anatômica

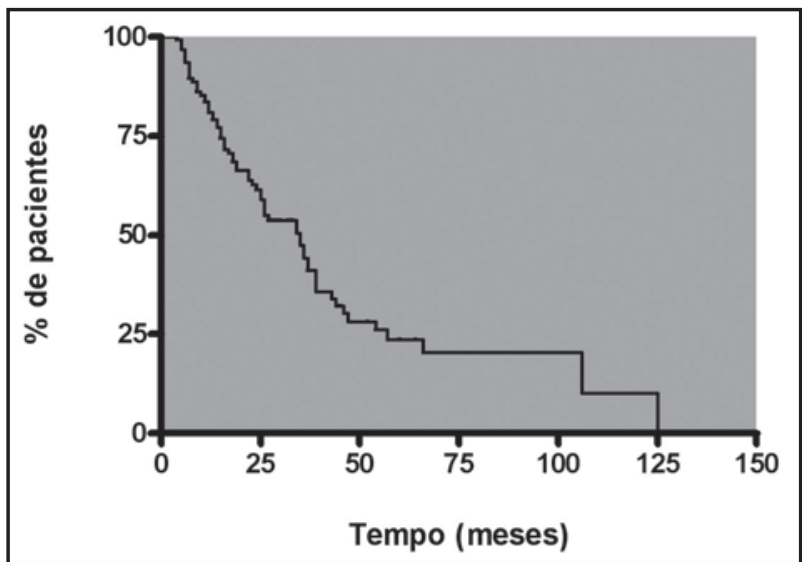

Figura 3 - Sobrevida global dos pacientes estudados

Tabela 3

Incidência de recidivas, metástases regionais e metástases à distância conforme a regiäo

\begin{tabular}{lccc}
\hline Região anatômica & Recidiva $(\%)$ & Metástase regional $(\%)$ & Metástase à distância (\%) \\
Língua & $17(17,9)$ & $24(25,3)$ & $5(5,3)$ \\
Assoalho & $27(29,4)$ & $33(35,9)$ & $4(4,4)$ \\
Lábio inferior & $14(23)$ & $13(21,3)$ & - \\
Palato & $14(28)$ & $19(38)$ & $2(4)$ \\
Retromolar & $6(30)$ & $9(45)$ & $1(5)$ \\
Mucosa jugal & $4(36,4)$ & $4(36,4)$ & $1(9,1)$ \\
Gengiva & $2(25)$ & $5(62,5)$ & $2(25)$ \\
Lábio superior & - & $1(33,3)$ & - \\
Total & $84(24,7)$ & $108(31,8)$ & $15(4,4)$ \\
\hline
\end{tabular}




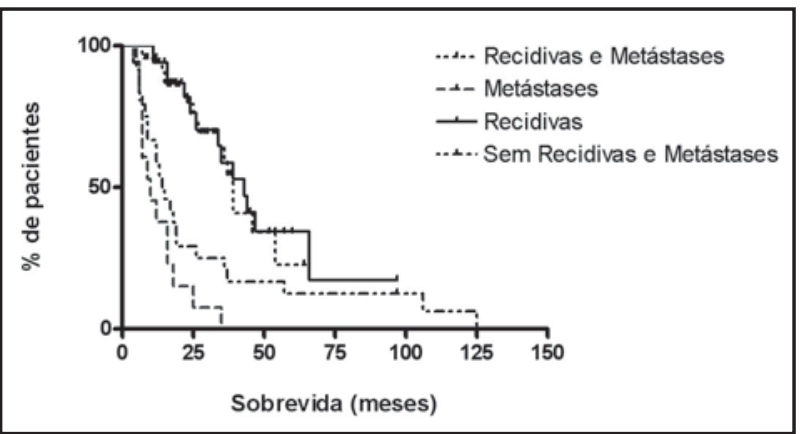

Figura 4 - Sobrevida dos pacientes com recidivas, metástases, recidivas e metástases ou ausência de ambos

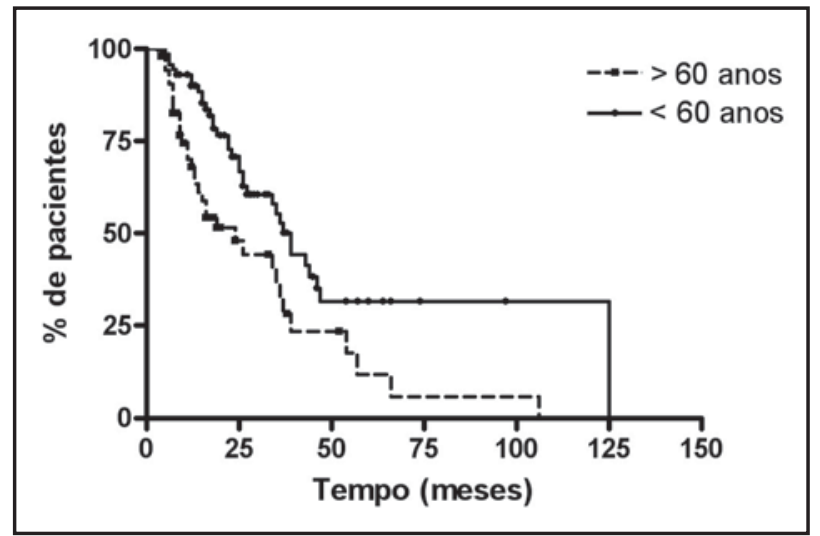

Figura 5 - Sobrevida dos pacientes segundo a idade

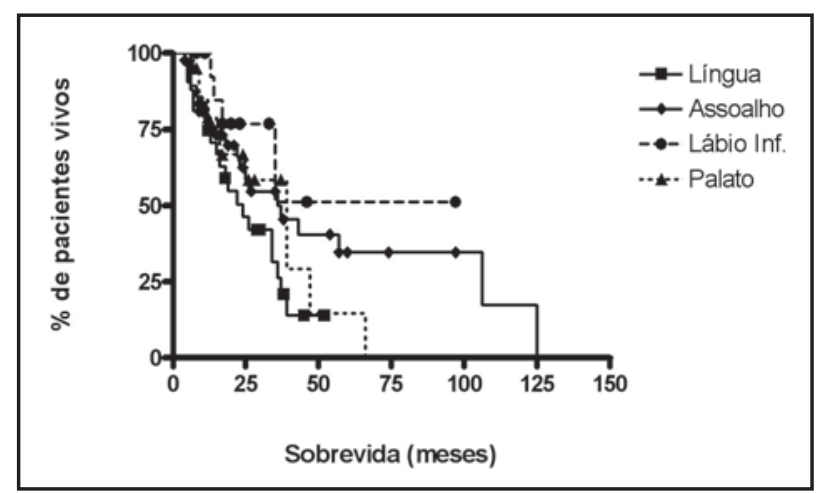

Figura 6 - Sobrevida dos pacientes nas quatro regiões anatômicas de maior incidência

\section{Discussão}

Os resultados obtidos acompanham outros estudos nacionais, onde Pithan et al. ${ }^{(39)}$ encontraram 400 casos em 26 anos de estudo e Souza et al. ${ }^{(45)}$ estudaram 654 casos num período de 22 anos. Em um outro estudo retrospectivo de $11 \operatorname{anos}^{(13)}$ foi relatada a ocorrência de 740 casos. No entanto, esses estudos incluem também algumas lesões em orofaringe, como palato mole e base de língua.

A distribuição dos pacientes conforme a idade foi concordante com outros trabalhos da literatura ${ }^{(33,45)}$, com um pico de incidência na sexta década de vida. Embora alguns estudos indiquem aumento da prevalência do carcinoma oral em adultos jovens ${ }^{(23,25)}$, a incidência encontrada em nosso trabalho não foi tão alta $(8,5 \%)$, semelhante à do estudo de Martin-Granizo et al. ${ }^{(27)}$.

O gênero masculino é provavelmente mais acometido pela maior exposição aos agentes cancerígenos associados a esse tipo de doença(11). A distribuição homem/mulher encontrada $(5,4: 1)$ foi maior do que a relatada em outros $\operatorname{estudos}^{(6,13,33,39,45)}$. Quanto à interação entre gênero, idade e incidência da neoplasia, são nítidas as alterações antes e após os 60 anos, de 9:1 para 3,2:1, respectivamente. Entretanto, essa interação também foi encontrada por outros autores $^{(6,16,37)}$, indicando um nítido aumento na prevalência da doença para o gênero feminino após os 60 anos, sugerindo que, além das diferenças na expectativa de vida, as mulheres expõem-se em menor quantidade ou mais tardiamente aos fatores de risco da doença.

Em estudo anterior realizado na população brasileira(13) o uso exclusivo do tabaco nos pacientes estudados $(31,9 \%)$ foi superior ao encontrado pelo nosso (18,5\%). Por outro lado, em nossa casuística, $68,5 \%$ dos pacientes relataram a combinação de tabaco e álcool, dados um pouco superiores aos encontrados no estudo mencionado $(63,8 \%)^{(13)}$. Apesar de os dois fatores de risco estarem também associados ao prognóstico da doença ${ }^{(4,26)}$, assim como no estudo de Kerdpon e Sriplung ${ }^{(20)}$, não encontramos influência significativa desses hábitos na ocorrência das recidivas e metástases.

A língua, o assoalho bucal e o lábio inferior são as localizações mais comumente relatadas nos estudos de câncer bucal| ${ }^{(11,13,29,33)}$. Em concordância com a literatura, encontramos na língua a topografia mais freqüente, com $27,9 \%$ dos $\operatorname{casos}^{(11,13,21,33,39)}$.

A irritação crônica é considerada por alguns autores um fator carcinogênico promotor do carcinoma epidermóide oral ${ }^{(43)}$. Recentemente, Pérez et al. ${ }^{(36)}$ mostraram experimentalmente que úlceras orais traumáticas crônicas podem atuar na promoção tumoral das regiões com alterações genéticas tumorais já iniciadas. Na cavidade oral, carcinógenos, como tabaco e álcool, podem desencadear a iniciação tumoral sobre extensas áreas causando o conhecido fenômeno de cancerização em campo ${ }^{(44)}$. Encontramos diferença significativa nos relatos de trauma entre as regiões anatômicas analisadas, sendo o palato duro a região mais relacionada (46\%).

Apesar de serem escassos os estudos associando o perfil dos pacientes conforme o tempo de evolução das lesões, é consenso na literatura que os pacientes diagnosticados em 
estágio tardio da doença têm maiores índices de mortalida$\mathrm{de}^{(33)}$. De acordo com Kowalski e Souza(22), as causas mais importantes no atraso do diagnóstico são a evolução inicial oligossintomática, o reduzido conhecimento sobre a doença entre pacientes e profissionais, o medo do diagnóstico e as dificuldades ao acesso médico. $O$ tempo médio que os pacientes demoram a procurar cuidados profissionais varia de três a cinco meses para o câncer bucal ${ }^{(49)}$, contudo o tempo médio encontrado em nosso estudo foi de 13 meses, principalmente devido ao atraso no diagnóstico das lesões labiais. Foi encontrada correlação significativa entre esse tempo e a topografia da lesão, sendo as lesões labiais diagnosticadas mais tardiamente do que as das outras regiões. Segundo Antunes e Antunes (2), os lábios são freqüentemente acometidos por enfermidades, como herpes, úlceras simples, fissuras e granulomas. Tal fato sugere que, possivelmente, a alta freqüência de lesões benignas possa levar o paciente a postergar a procura profissional.

Os pacientes sem recidivas e metástases em nosso estudo tiveram sobrevida maior do que aqueles que apresentaram recidivas, metástases ou ambas. O risco de ocorrência de recidivas ou de um segundo tumor primário varia de $4,3 \%$ a $30 \%{ }^{(18)}$ e a incidência de metástases cervicais relatada na literatura varia de $35,3 \%$ a $60 \%(30,32,50)$. A incidência de recidivas encontrada em nosso trabalho $(24,7 \%)$ não diferiu da literatura. Entretanto, a ocorrência das metástases cervicais $(31,8 \%)$ mostrou-se inferior a outros estudos.

A padronização da idade para caracterização da população idosa não é consenso na literatura. No entanto, apesar de vários autores optarem por valores mais amplos, foi utilizado o critério da Organização Mundial da Saúde (OMS), que indica a idade de 60 anos como início da terceira idade nos países em desenvolvimento ${ }^{(42)}$. Ao contrário de outro estudo ${ }^{(37)}$, foi encontrado um comportamento diferente entre os grupos de idade, mostrando diferenças significativas nas curvas de sobrevivência, sugerindo que a diminuição da sobrevida nos mais idosos pode ocorrer devido à maior incidência de doenças debilitantes, maiores seqüelas pós-tratamento e complicações associadas ao envelhecimento.

A taxa de sobrevida global em cinco anos foi de apenas $24 \%$, próxima à encontrada para negros americanos com essa doença $(27,6 \%)^{(28)}$. Assim como em outros estudos ${ }^{(12,51)}$, as lesões linguais tiveram as piores taxas de sobrevida. Além disso, apresentaram a maior discrepância com relação à incidência de metástases regionais em comparação com outros trabalhos ${ }^{(5,50)}$. Existe um subgrupo de pequenos tumores iniciais que se comportam de uma maneira agressiva inesperada ${ }^{(3)}$. Segundo Okada et al.(32), mesmo nas lesões primárias T1 e T2 do carcinoma epidermóide oral podem ocorrer metástases regionais em linfonodos, e na literatura existem muitos estudos evidenciando a ocorrência de gânglios cervicais patologicamente positivos em pacientes sem evidências clínicas da doença ${ }^{(15,24)}$, sugerindo que essas ocorrências, possivelmente subestimadas em nossos registros, podem ter influenciado as taxas de sobrevida.

A incidência do carcinoma epidermóide oral nessa população específica acometeu em sua maioria um perfil de pacientes masculinos na sexta década de vida, com aumento significativo para o gênero feminino e menor sobrevida após essa faixa etária. Foi encontrado um número expressivo de tabagistas e etilistas, sobretudo naqueles que relataram traumatismo crônico por próteses mal adaptadas. A língua foi a região de maior incidência, e os pacientes com lesões labiais tiveram maior atraso na procura pelo tratamento.

Os baixos índices de sobrevida encontrados refletem a necessidade de maior atenção ao câncer bucal nessa população. A investigação do perfil e da sobrevivência dos pacientes de acordo com as regiões anatômicas específicas fornece bases científicas para orientar campanhas de prevenção educativas para o diagnóstico precoce e tratamento dessa doença, que quase sempre começa num local de fácil visualização e inspeção para o próprio paciente.

\section{Referências}

I. ANTONIADES, D. Z. et al. Squamous cell carcinoma of the lips in a northern Greek population. Evaluation of prognostic factors on 5-year survival rate - I. Eur J Cancer B Oral Oncol, v. 3।B, n. 5, p. 333-9, 1995.

2.ANTUNES,A.A.;ANTUNES,A. P. Estudo retrospectivo e revisão de literatura dos tumores dos lábios: experiência de 28 anos. Rev Bras Cancerol, v. 50, n. 4, p. 295-300, 2004.
3. ASAKAGE, T. et al.Tumor thickness predicts cervical metastasis in patients with stage I/II carcinoma of the tongue. Cancer, v. 82, n. 8, p. I443-8, 1998.

4. BUNDGAARD, T.; BENTZEN, S. M.; WILDT, J. The prognostic effect of tobacco and alcohol consumption in intra-oral squamous cell carcinoma. Eur J Cancer B Oral Oncol, v. 30B, n. 5, p. 323-8, 1994. 
5. CARVALHO, A. L. et al. Cancer of the oral cavity: a comparison between institutions in a developing and a developed nation. Head Neck, v. 26, n. I, p. 3I-8, 2004.

6. CARVALHO, M. B. et al. Características clínico-epidemiológicas do carcinoma epidermóide de cavidade oral no sexo feminino. Rev Assoc Med Bras, v. 47, n. 3, p. 208- I4, 2001.

7. CHARABI, B. et al. Oral cancer: results of treatment in the Copenhagen University Hospital. Acta Otolaryngol Suppl, v. 543, p. 246-7, 2000.

8. COSTA, A. L. L. et al. Correlação entre a classificação TNM, gradação histológica e localização anatômica em carcinoma epidermóide oral. Pesqui Odontol Bras, v. 16, n. 3, p. 216-20, 2002.

9. COTRAN, R. S.; KUMAR, V.; COLLINS, T. Robbins Patologia Estrutural e Funcional. 6 ed. Rio de Janeiro, Rj: Guanabara Koogan, 2000.

10. COX, B.; TAYLOR, K.; TREASURE, E. Trends in oral cancer by subsite in New Zealand. Eur J Cancer B Oral Oncol, v. 3 IB, n. 2, p. I 13-7, 1995.

I I. DEDIVITIS, R. A. et al. Características clínico-epidemiológicas no carcinoma espinocelular de boca e orofaringe. Rev Bras Otorrinolaringol, v. 70, n. I, p. 35-40, 2004.

I2. FRANCO, E. L. et al. Race and gender influences on the survival of patients with mouth cancer. J Clin Epidemiol, v. 46, n. I, p. 37-46, 1993.

13. GERVASIO, O. L. et al. Oral squamous cell carcinoma: a retrospective study of 740 cases in a Brazilian population. Braz Dent J, v. 12, n. I, p. 57-61, 2001.

14. HA, P. K., CALIFANO, J. A. The role of human papillomavirus in oral carcinogenesis. Crit Rev Oral Biol Med, v. I5, n. 4, p. I88-96, 2004

15. HICKS, W. L. et al. Surgery as a single modality therapy for squamous cell carcinoma of the tongue. Am J Otolaryngol, v. 19, n. I, p. 24-8, 1998.

16. HOROWITZ,A. M. et al. The need for health promotion in oral cancer prevention and early detection.J Public Health Dent, v. 56, n. 6, p. 319-30, 1996.

17. BRASIL. Ministério da Saúde. Instituto Nacional de Câncer. Estimativa 2005: incidência de câncer no Brasil. Rio de Janeiro (Brasil): INCA, 2004.

18. JONES, A. S. et al.The level of cervical lymph node metastases: their prognostic relevance and relationship with head and neck squamous carcinoma primary sites. Clin Otolaryngol Allied Sci, v. 19, n. I, p. 63-9, 1994.

19. KAPLAN, E. L.; MEIER, P. Nonparametric estimation from incomplete observations. J Am Stat Assoc, v. 53, p. 457-8I, 1958.

20. KERDPON, D.; SRIPLUNG, H. Factors related to advanced stage oral squamous cell carcinoma in Southern Thailand. Oral Oncol, v. 37, n. 3, p. 216-21, 2001

2I. KOWALSKI, L. P. et al. Lateness of diagnosis of oral and oropharyngeal carcinoma: factors related to the tumor, the patient and health professionals. Eur J Cancer B Oral Oncol, v. 30B, n. 3, p. 167-73, 1994.

22. KOWALSKI, I. S. G.; SOUZA, C. P. Social representations of relatives and patients with oral and oropharyngeal squamous carcinoma on the prevention and diagnosis of cancer. Acta
Oncol Bras, v. 21, n. I, p. 206-10, 2001.

23. LLEWELLYN, C. D.; JOHNSON, N.W.; WARNAKULASURIYA, K. A. Risk factors for squamous cell carcinoma of the oral cavity in young people - a comprehensive literature review. Oral Oncol, v. 37, n. 5, p. 401-18, 2001.

24. LYDIATT, D. D. et al. Treatment of stage I and II oral tongue cancer. Head Neck, v. I5, n. 4, p. 308-12, 1993.

25. LYPE, E. M. et al. Oral cancer among patients under the age of 35 years. J Postgrad Med, v. 47, n. 3, p. 171-6, 2001.

26. MANSOUR, O.I.; SNYDERMAN, C.H.; D'AMICO, F.Association between tobacco use and metastatic neck disease. Laryngoscope, v. I I3, n. I, p. |61-6, 2003.

27. MARTIN-GRANIZO, R. et al. Squamous cell carcinoma of the oral cavity in patients younger than 40 years. Otolaryngol Head Neck Surg, v. I 17, n. 3, Pt. I, p. 268-75, 1997.

28. MOORE, R. J. et al. Racial disparity in survival of patients with squamous cell carcinoma of the oral cavity and pharynx. Ethn Health, v. 6, n. 3-4, p. 165-177, 2001.

29. MOREIRA, C.A. et al. Epidemiologia do carcinoma espinocelular da boca: análise de 244 casos. Rev Paul Odontol, v. 19, n. 6, p. 24-7, 1997.

30. NAKAYAMA,A. et al. Relation between lymphatic vessel diameter and clinicopathologic parameters in squamous cell carcinomas of the oral region. Cancer, v. 86, n. 2, p. 200-6, 1999.

31. NEVILLE, B.W. et al. Patologia oral \& maxilofacial. I ed. Rio de Janeiro, RJ: Guanabara Koogan, 1998.

32. OKADA, Y. et al. An analysis of cervical lymph nodes metastasis in oral squamous cell carcinoma. Relationship between grade of histopathological malignancy and lymph nodes metastasis. J Oral Maxillofac Surg, v. 32, n. 3, p. 284-88, 2003.

33. OLIVER, A. J.; HELFRICK, J. F.; GARD, D. Primary oral squamous cell carcinoma: a review of 92 cases. J Oral Maxillofac Surg, v. 54, n. 8, p. 949-54, 1996.

34. ORD, R. A. Discussion. Primary oral squamous cell carcinoma: a review of 92 cases. J Oral Maxillofac Surg, v. 54, n. 8, p. 955, 1996.

35. PARKIN, D. M. et al. Global cancer statistics, 2002. CA Cancer J Clin, v. 55, n. 2, p. 74- I08, 2005.

36. PEREZ, M. A.; RAIMONDI, A. R.; ITOIZ, M. E. An experimental model to demonstrate the carcinogenic action of oral chronic traumatic ulcer.J Oral Pathol Med, v. 34, n. I, p. I722, 2005.

37. PERUSSI, M. R. et al. Carcinoma epidermóide da boca em idosos de São Paulo. Rev Assoc Med Bras, v. 48, n. 4, p. 34 I4, 2002.

38. PINHEIRO, G. C. D. et al. Prevenção do câncer bucal. Bragança Paulista, SP: Encadernadora Pietro, 1998.

39. PITHAN, S. A. et al. Perfil epidemiológico do carcinoma espinocelular de boca em pacientes do Serviço de Estomatologia do Hospital São Lucas da PUCRS. Revista Odonto Ciênc, v. 19, n. 44, p. 126-30, 2004.

40. REGEZI, J. A.; SCIUBBA, J. J. Patologia bucal: correlações clinicopatológicas. I ed. Rio de Janeiro, RJ: Guanabara Koogan, 1991.

4I. ROTHMAN, K.J.The proportion of cancer attributable to alcohol consumption. Prev Med, v. 9, n. 2, p. 174-9, 1980.

42. SARINI, J. et al. Head and neck squamous cell carcinoma in 
elderly patients. Arch Otolaryngol Head Neck Surg, v. 127, n. 9, p. 1089-92, 2001.

43. SCIUBBA, J.J. Oral cancer.The importance of early diagnosis and treatment. Am J Clin Dermatol, v. 2, n. 4, p. 239-5I, 2001.

44. SLAUGHTER, D. P.; SOUTHWICK, H. W.; SMEJKAL, W. Field cancerization in oral stratified squamous epithelium: clinical implications of multicentric origin. Cancer, v. 6, n. 5, p. 963-8, 1953.

45. SOUZA, A. et al. Epidemiologia do carcinoma epidermóide da mucosa bucal - contribuição ao estudo sobre três variáveis: sexo, faixa etária e raça. Rev Odontol UNICID, v. 8, n. 2, p. 127-34, 1996.

46. SUGERMAN, P. B.; SAVAGE, N. W. Oral cancer in Australia: 1983-1996. Aust Dent J, v. 47, n. I, p. 45-56, 2002.

47. SYRJANEN, S. Human papillomavirus (HPV) in head and neck
cancer.J Clin Virol, v. 32, Suppl. I, p. S59-66, 2005.

48. TRALONGO, V. et al. Prognostic factors in oral squamous cell carcinoma. A review of the literature. Anticancer Res, v. 19, n. 4C, p. 3503-10, 1999

49. WILDT, J.; BUNDGAARD, T.; BENTZEN, S. M. Delay in the diagnosis of oral squamous cell carcinoma. Clin Otolaryngol Allied Sci, v. 20, n. I, p. 2 1-5, 1995.

50. WOOLGAR, J. A. Histological distribution of cervical lymph node metastases from intraoral/oropharyngeal squamous cell carcinomas. Br J Oral Maxillofac Surg, v. 37, n. 3, p. 175 80, 1999.

5I. WUNSCH-FILHO, V. The epidemiology of oral and pharynx cancer in Brazil. Oral Oncol, v. 38, n. 8, p. 737-46, 2002. 